\title{
DIRECT SYNTHESIS OF PYRAZOLO[4,3-e][1,2,4]TRIAZINE DERIVATIVES FROM OXIMES OF 5-ACYL AND 5-FORMYL-1,2,4-TRIAZINES ${ }^{1}$
}

\author{
Mariusz Mojzych and Andrzej Rykowski* \\ Department of Chemistry, University of Podlasie, 08-110 Siedlce, Poland
}

\begin{abstract}
Deprotection of carbonyl functionality in oximes of 5-acyl and 5-formyl-1,2,4-triazines followed by condensation with hydrazine or substituted hydrazine and subsequent intramolecular ring closure of the resulting hydrazones of 5-acyl and 5-formyl-1,2,4-triazines were achieved in a domino fashion to afford the pyrazolo[ $[4,3-e][1,2,4]$ triazine derivatives.
\end{abstract}

\section{Introduction}

The interesting biological activity of naturally occurring pyrazolo[4,3-e][1,2,4]triazine derivatives ${ }^{2}$ and the fact that there are no simple synthetic pathways starting from easily available reactants prompted us to develop a convenient one-step synthesis of this heterocyclic system. The approach is based on the intramolecular ring closure of hydrazones ${ }^{3}$ or substituted hydrazones ${ }^{4}$ of 5-acyl-1,2,4-triazines (4) involving nucleophilic substitution of hydrogen at C-6 of 1,2,4-triazine ring by the hydrazine nitrogen. The required hydrazones 4 were prepared in a three steps synthesis using literature procedures, namely (i) regioselective acylation of 1,2,4-triazine (1) with nitronate ion into the corresponding oxime (2), ${ }^{5}$ (ii) deprotection of carbonyl functionality in $2,{ }^{6}$ and (iii) condensation of the resulting 5-acyl-1,2,4-triazine (3) with hydrazine or substituted hydrazine derivative. ${ }^{4}$ The overall synthetic strategy is shown in Scheme 1 (route b).

Although the method seems to be useful for preparation of functionalized pyrazolo $[4,3-e][1,2,4]$ triazines, the necessity of deprotection of carbonyl group in 2 followed by the condensation of the 5-acyl-1,2,4triazine (3) thus obtained with a hydrazine derivative at the latter stage, make the sequence somewhat lengthy. To achieve the synthesis in a shorter way, a systematic study was undertaken for the construction of pyrazolo[4,3-e][1,2,4]triazines (5) directly from oximes of 5-acyl or 5-formyl-1,2,4-triazines (2) and the corresponding hydrazine derivatives, under acidic conditions (Scheme 1, route a) 


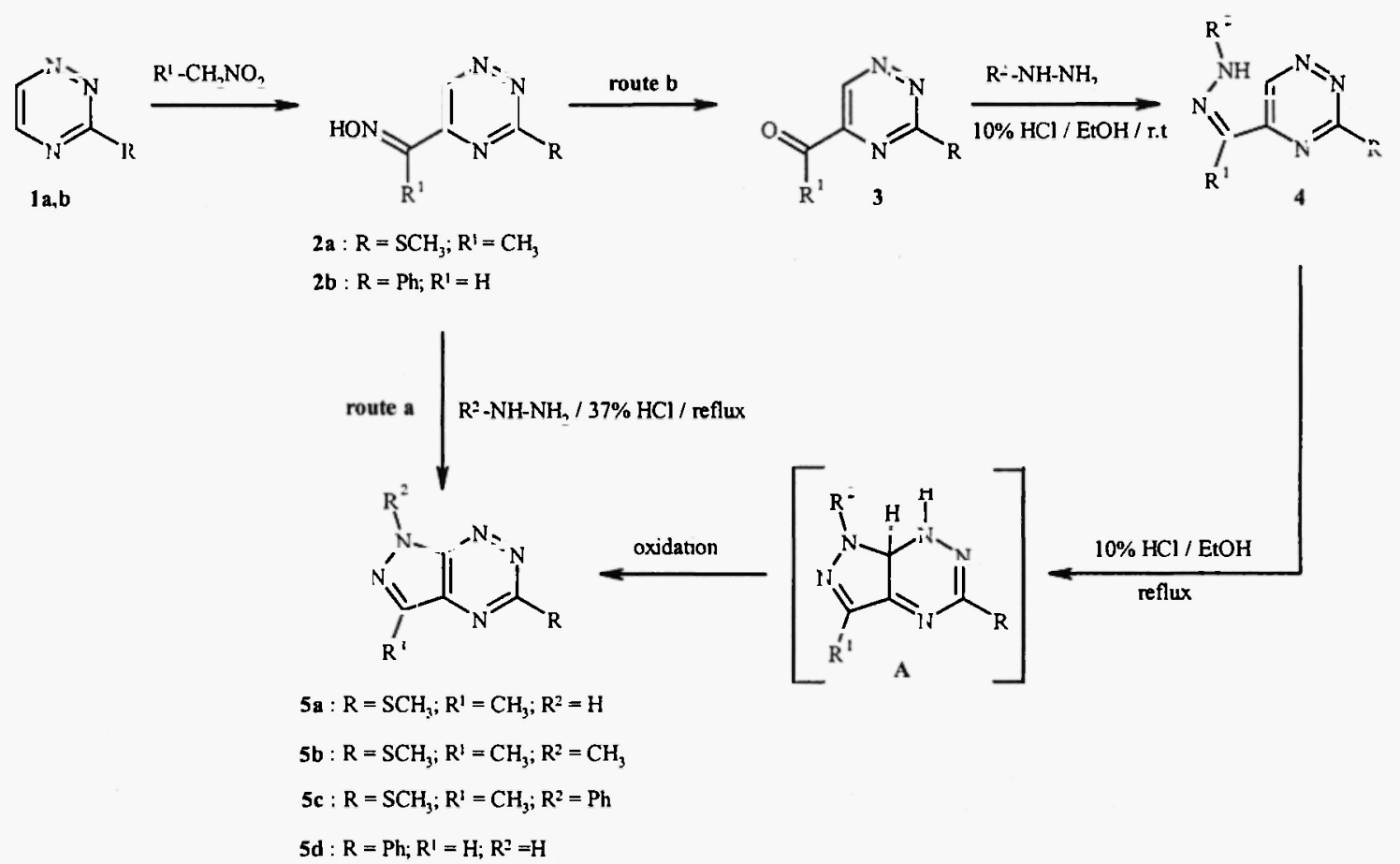

Scheme-1

\section{Results and Discussion}

Attempts were first made by heating the oxime of 5-acetyl-3-(methylsulfanyl)-1,2,4-triazine (2a) with hydrazine hydrochloride $\left(\mathrm{R}^{2}=\mathrm{H}\right)$ in ethanol at reflux, varying the concentration of hydrochloric acid and the reaction time. The progress of the reaction was monitored by TLC. Whereas with $10 \%$ hydrochloric acid only traces of the expected product could be detected by TLC, use of $37 \%$ hydrochloric acid furnished the desired 3-methyl-5-(methylsulfanyl)- $1 H$-pyrazolo[4,3-e][1,2,4]triazine (5a) in $27 \%$ yield after five hours. The synthesis proceeds in a domino fashion involving deprotection of $\mathbf{2 a}$, formation of hydrazone derivative and acid promoted ring-closure of the latter via bicyclic intermediate $\mathbf{A}$ (see Scheme 1 , route b).

Likewise, treatment of $2 \mathbf{a}$ with methylhydrazine $\left(\mathrm{R}^{2}=\mathrm{CH}_{3}\right)$ or phenylhydrazine hydrochloride $\left(\mathrm{R}^{2}=\mathrm{Ph}\right)$ under conditions mentioned above, afforded $\mathrm{N}-1$ substituted pyrazolo[4,3-e][1,2,4]triazines $\mathbf{5 b}$ and $\mathbf{5 c}$, respectively. Attempt to increase the yields failed, even when long times were used. The same reaction conditions were applied to produce 5-phenyl-1 $H$-pyrazolo[4,3-e][1,2,4]triazine (5d) by subjecting the oxime of 5-formyl-3-phenyl-1,2,4-triazine $(\mathbf{2 b})$ to reaction with hydrazine hydrochloride $\left(\mathrm{R}^{2}=\mathrm{H}\right)$. 
Although 5-formyl-3-phenyl-1,2,4-triazine could not be obtained by cleavage of hydroxyimino functionality in $\mathbf{2 b},{ }^{7}$ the reaction proceeded clearly and $\mathbf{5 d}$ was obtained in $65 \%$ yield after purification by chromatography.

In summary, the synthesis of pyrazolo[4,3-e][1,2,4]triazine derivatives 5 directly from easily available oximes of 5-acyl or 5-formyl-1,2,4-triazines 2 was accomplished in shorter steps then those recorded in the earlier reports. ${ }^{3.4}$ Further work is in progress to test the generality of this approach for preparation $1,3-$ unsubstituted pyrazolo[4,3-e][1,2,4]triazine derivatives.

\section{Experimental}

Melting points were determined on Boethius melting point apparatus and are uncorrected. IR spectra were measured with a Magna IR-760 spectrophotometer. ${ }^{1} \mathrm{H}-\mathrm{NMR}$ spectra were recorded in deuteriochloroform on a Varian Gemini $200 \mathrm{MHz}$ spectrometer. Chemical shifts are expressed in ppm with reference to TMS as an internal standard. Coupling constants are given in hertz (Hz). MS spectra were measured on AMD 604 spectrometer [electron impact (EI)]. Elemental analyses were recorded on Perkin-Elmer $2400-\mathrm{CHN}$ analyzer and the results for the indicated elements were within $0.3 \%$ of the calculated values.

Preparation of $1 H$-pyrazolo[4,3-e][1,2,4]triazines (5a-d) from oximes $2 \mathrm{a}$ and $2 \mathrm{~b}$ - general procedure.

To a solution of the oxime $\mathbf{2 a}$ or $\mathbf{2 b}(1 \mathrm{mmol})$ and the corresponding hydrazine $(2 \mathrm{mmol})$ in ethanol $(8 \mathrm{~mL}) 37 \%$ hydrochloric acid $(0.5 \mathrm{~mL})$ was added. The resulting mixture was refluxed until the starting material disappeared ( $1-5 \mathrm{~h}$, TLC control). Then the solvent was removed in vacuo to dryness and the crude product was purified by column chromatography on silica gel using chloroform/acetone mixture $(50: 1)$ as eluent to give 5a-d.

\section{3-Methyl-5-(methylsulfanyl)-1H-pyrazolo $[4,3-e][1,2,4]$ triazine 5a:}

Yield 27\%; mp $165^{\circ} \mathrm{C} ;{ }^{1} \mathrm{H}-\mathrm{NMR}\left(\mathrm{CDCl}_{3}\right) \delta 2.67(\mathrm{~s}, 3 \mathrm{H}), 2.74(\mathrm{~s}, 3 \mathrm{H}), 11.05(\mathrm{~s}, 1 \mathrm{H})$;

IR (KBr) $3100 \mathrm{~cm}^{-1}(\mathrm{NH})$; MS (El, 70eV, $\left.m / z, \%\right)$ : $181(36)\left[\mathrm{M}^{+}\right], 153(98), 152(49), 126(41), 112(46)$, 97 (41), 85 (58), 70 (100). Anal. Calcd for $\mathrm{C}_{6} \mathrm{H}_{7} \mathrm{~N}_{5} \mathrm{~S}: \mathrm{C}, 39.77 ; \mathrm{H}, 3.86 ; \mathrm{N}, 38.67$. Found: C, 39.93; $\mathrm{H}$, $3.75 ; \mathrm{N}, 38.45$.

1,3-Dimethyl-5-(methylsulfanyl)-1 $H$-pyrazolo[4,3-e][1,2,4]triazine (5b):

Yield $13 \% ; \mathrm{mp} 123{ }^{\circ} \mathrm{C} ;{ }^{\mathrm{l}} \mathrm{H}-\mathrm{NMR}\left(\mathrm{CDCl}_{3}\right) \delta 2.62(\mathrm{~s}, 3 \mathrm{H}) ; 2.73(\mathrm{~s}, 3 \mathrm{H}) ; 4.24(\mathrm{~s}, 3 \mathrm{H})$;

MS (EI, 70eV, $m / z, \%): 195(20)\left[\mathrm{M}^{+}\right], 152(30), 70(100)$.

Anal. Calcd for $\mathrm{C}_{7} \mathrm{H}_{9} \mathrm{~N}_{5} \mathrm{~S}: \mathrm{C}, 43.07 ; \mathrm{H}, 4.61 ; \mathrm{N}, 35.89$. Found: $\mathrm{C}, 43.06 ; \mathrm{H}, 4.62 ; \mathrm{N}, 35.95$. 


\section{3-Methyl-5-(methylsulfanyl)-1-phenyl-1 $H$-pyrazolo[4,3-e][1,2,4]triazine (5c):}

Yield $18 \%$; mp $105^{\circ} \mathrm{C} ;{ }^{1} \mathrm{H}$ NMR $\left(\mathrm{CDCl}_{3}\right) \delta 2.73(\mathrm{~s}, 3 \mathrm{H}), 2.77(\mathrm{~s}, 3 \mathrm{H}), 7.29-7.40(\mathrm{~m}, \mathrm{H}), 7.50-7.61(\mathrm{~m}$, 2H), 8.31-8.38 (m, 2H); MS (EI 70eV, m/z,\%): $257(43)\left[\mathrm{M}^{+}\right], 232(3), 216(22), 93(41), 77$ (100).

Anal. Calcd for $\mathrm{C}_{12} \mathrm{H}_{11} \mathrm{~N}_{5} \mathrm{~S}$ : C, 56.03; H, 4.28; N, 27.23. Found: C, 55.67; H, 4.13; N, 27.05.

\section{5-Phenyl-1 $H$-pyrazolo $[4,3-e][1,2,4]$ triazine (5d):}

Yield 65\%; mp 214-216 ${ }^{\circ} \mathrm{C} ;{ }^{1} \mathrm{H}-\mathrm{NMR}\left(\mathrm{CDCl}_{3}\right) \delta$ 7.55-7.58 (m, 3H), $8.47(\mathrm{~s}, 1 \mathrm{H}), 8.59-8.64(\mathrm{~m}, 2 \mathrm{H})$, 11.25 (s, 1H); IR (KBr) $3120 \mathrm{~cm}^{-1}(\mathrm{NH})$; MS (EI, 70eV, m/z, \%): 197 (5) [M ], 169 (76), 142 (52), 115 (100). Anal. Calcd for $\mathrm{C}_{10} \mathrm{H}_{7} \mathrm{~N}_{5}: \mathrm{C}, 60.68 ; \mathrm{H}, 3.55 ; \mathrm{N}, 35.53$. Found: $\mathrm{C}, 60.79 ; \mathrm{H}, 3.64 ; \mathrm{N}, 35.47$.

\section{References}

1. Part 34 in 1,2,4-Triazines in Organic Synthesis. For part 33, see D. Branowska, I. Buczek, K. Kalinska, J. Nowaczyk, and A. Rykowski, Tetrahedron Lett. 46, 8539 (2005).

2. (a) K. Hirata, H. Nakagami, J. Takashina, T. Mahmud, M. Kobayashi, Y. In, T. Ishida, and K. Miyamoto, Heterocycles, 43, 1513 (1996); (b) V.V. Smirnov, E.A. Kiprianowa, A.D. Garagulya, S.E. Esipov, and S.A. Dovjenko, FEMS Microbiology Lett. 153, 357 (1997).

3. M. Mojzych and A. Rykowski, Polish J. Chem. 77, 1797 (2003).

4. A. Rykowski, M. Mojzych, and Z. Karczmarzyk, Heterocycles 53, 2175 (2000).

5. A. Rykowski and T. Lipinska, Synth.Commun. 26, 4409 (1996) and references cited therein.

6. A. Rykowski, E. Olender, D. Branowska and H.C. van der Plas, Organic Preparations and Procedures Int. 33(5), 501 (2001).

7. A. Rykowski, E. Guzik, M. Makosza, and W. Holzer, J. Heterocyclic Chem. 30, 413 (1993).

Received on November 20, 2005 